\title{
Physical Activity Level Among Universitas Pendidikan Indonesia's Lecturers
}

\author{
Imas Damayanti*, Madrais, Yati Ruhayati, Nur Indri Rahayu \\ Departemen Pendidikan Kesehatan dan Rekreasi, Universitas Pendidikan Indonesia \\ Bandung, Indonesia \\ *Imas_upi@edu
}

\begin{abstract}
The research aim on surveying the prevalence on physical inactivity in Indonesian Universities lecturers. It is population-based study, using stratified random sampling. A total of 120 lecturers will be interviewed using Global Physical Questionnaire (GPAQ). The average MET of UPI teaching staff is 3758 MET. The highest MET average is from the Faculty of Physical Education. The lowest MET is from the faculties of economic and business education which is 927 MET.
\end{abstract}

Keywords: GPAQ, Indonesian lecturers, physical activity, population based

\section{INTRODUCTION}

The benefits and benefits of active life are already very well known by the public and proven by academic research. Humans, mostly health matters. Physical activity can maintain and improve cardiovascular fitness, muscle strength and endurance, joint strength, bone strength and body composition [1]. In the end, physical activities carried out correctly in accordance with those recommended by institutions are believed to increase the status of physical respect for individuals and society.

Adequate physical fitness status consists of all people, both young, old, male, female, in the city, in the village, executive groups as well as ordinary people. Everyone knows that adequate physical fitness is needed by everyone in order to fulfill their maximum daily tasks. In a company, with adequate physical fitness status, a janitor can do his job well, an accountant employee can manage and be careful in administration, while a manager can think clearly in search of new innovations for company development. In other words, physical fitness is required by freedom in any position in the company.

Awareness of the importance of physical fitness is increasingly increasing. Various active and healthy lifestyle promotion programs to improve physical fitness are also increasingly provided by both the government and the private sector, such as healthy walking, cycling, healthy exercise programs, and fitness programs at various fitness centers.

Making someone fit, whether children, adolescents, adults, or even seniors is actually not too difficult. There is enough evidence of the results of research that supports these statements both conducted at home and abroad in the environment of students and the wider community. Those who do physical activity with a frequency of 3-4 x per week, a minimum duration of 15 minutes per time, and moderate intensity, then within three months the results can be proven. The problem lies in the willingness to do a fitness program independently. Not a few research results show that athletes, students, and members of fitness centers, company employees have adequate physical fitness status when they are actively training. Furthermore, their fitness status declined after they no longer had the status of students, were no longer athletes, were no longer members of fitness centers or were no longer employees of certain companies. In other words, their fitness status decreases after they no longer actively do the fitness program in a 'forced' state by their status.

The most difficult and challenging thing actually makes physical activity a lifestyle that is carried out throughout life [2]. And this proved to be difficult, because it turned out that behind the increased awareness of the importance of physical activity, actually various chronic diseases, such as diseases caused by obesity, diabetes mellitus, stroke and so on, actually increased [3]. This shows that the general public, including the community in a company, is not as fit as ever, but is increasingly unfit. The survey results show that the physical fitness status of students and the people of Indonesia is still low and even tends to decline. Instead of being more active, it is increasingly inactive .

It's important to know the root of the problem to solve a problem. The problem of physical inactivity needs to be known the causes and obstacles to physical activity in order to get a sustainable solution. Research on community barriers to physical activity has been carried out, especially in developed countries. However, research in Indonesia and in specific populations has not been done much. These studies need to be done, one of which is in tertiary institutions that have quite a large number of members of the community and sustain life as a population. Members of a university community are generally well-informed, and may have suggestions for activities that are also sufficient. So this research needs to be done as an initial step to eradicate inactivity and ultimately improve physical fitness and prevent chronic illness. 


\section{METHOD}

This research was conducted for 8 months in 2019 at the Indonesian University of Education.

The research method used is descriptive survey. The study was conducted using a questionnaire instrument on the subject of research by distributing questionnaires directly through contact people at each Faculty throughout the Indonesian Education University.

\section{A. Research Subject}

The study population was all lecturers at the University of Indonesian Education Samples were taken by cluster random sampling. The total participants were 200 respondents. Gender taken from men and women.

\section{B. Data Collection Instruments}

1) International Physical Activity Questionnaire (IPAQ): All instruments are questionnaire instruments with validity and reliability that have been tested in a number of internationally accredited journals. For the purposes of this study, these instruments were adapted to Indonesian and retest their validity and reliability.

\section{RESULT}

Researchers took samples from UPI Bandung teaching staff from each faculty in UPI with the gender criteria of male and female working as teaching staff at UPI. Total 201 people. Consisting of instructors from 8 faculties at the University of Indonesian education.

From this study, the average level of physical activity of teaching staff at Indonesian education universities is moderate. The details of each faculty are as follows:

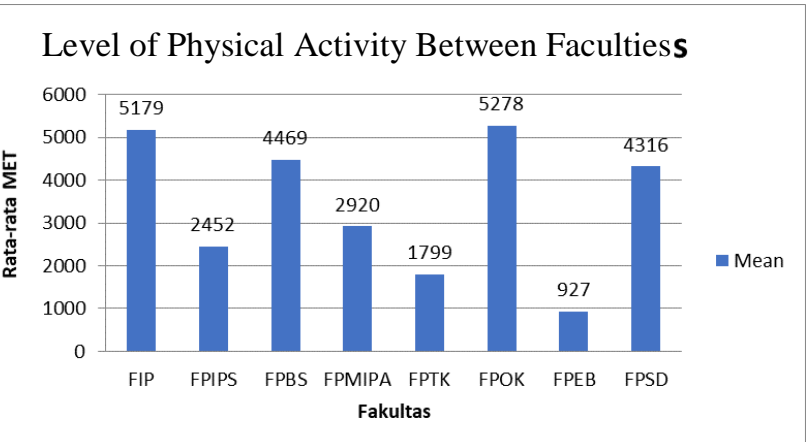

Fig. 1. Level of physical activity between faculties

The average MET of UPI teaching staff is 3758 MET. The highest MET average is from the Faculty of Physical Education. The lowest MET is from the faculties of economic and business education which is 927 MET.

\section{DISCUSSION}

The key word for an active lifestyle is "the more active a person is, the better". However, in the context of promoting active lifestyles, each country has their respective references. The US Department of Health and Human Services makes active lifestyle recommendations for children aged 6-17 years, the contents of which are physically active for a total of 60 minutes or more each day and must include at least three times a week doing exhaustive category aerobic activities, as well as covers varied physical activities [4]. While the physical activity guideline for adults in general is around 20 to 30 minutes, it's good every day, at least three times a week doing activities with moderate categories. To be clearer, Sallis and Patrick put forward, all adolescents ... be physically active daily, or nearly every day, as part of play, games, sports, work, transportation, recreation, physical education, or planned exercise, in the context of family, school, and community activities and that adolescents engage in three or more sessions per week of activities that last 20 minutes or more at a time and that require moderate to vigorous levels of exertion [5].

Pate said, every US adult should accumulate 30 minutes or more of moderate-intensity physical activity on the most, preferably al, days of the week [6]. Meanwhile, the Ministry of Health of the Republic of Indonesia put forward physical activity as follows, . . . is an activity carried out by residents aged 15 years and over that is 'heavy', 'moderate' and runs at least 10 minutes without interruption for each activity, and cumulative> 150 minutes for 5 days a week [7]. In order to improve the nation's health conditions, physical education can take part in making a positive and significant contribution to solving health problems, through the planting of healthy and active lifestyles to promote health and reduce the possibility of the emergence of various non-infectious diseases that have recently been very worrying about. Morris argues, physical activity is the best buy in public health [8].

\section{A. Physical Activity}

Physical activity is a variety of activities that involve bodily movements produced by skeletal muscles, and those movements produce energy expenditure [9]. Americal Aliance of Health, Physical Education, Recreation, and Dance (AAHPERD), suggests the definition of physical activity, "Physical activity is strictly defined as any bodily movement produced by skeletal muscles that results in an expenditure of energy [10]. This physical activity covers a fairly broad scope, which is fairly carried out in various types of work, leisure time activities, and daily routine activities. These activities can be categorized as activities that require light, moderate and heavy effort. Moderate activity is equivalent to brisk walking 3 to 4 MPH (Mile Per Hour). if one mile $=1.609$ kilometers, the estimated walking intensity is around 4.5 to 6.5 kilometers per hour, equivalent to 100 to 130 steps per minute. The activity can improve health if carried out regularly and carried out based on scientific principles. More simply it can be said that physical activities are various physical activities that are arranged, organized, and oriented towards physical health and fitness goals. For this reason, physical activity programs at school to improve fitness are not always in the form of sports activities that emphasize skills.

In general, physical fitness is often interpreted as the ability to be able to do daily work without experiencing excessive fatigue so that it still has enough energy to do pleasure or hobbies in spare time and also still has enough energy to do activities that are unexpected demands or sudden. The 
[2] Hubert HB, Bloch DA, Oehlert JW, Fries JF, "Lifestyle habits and compression of morbidity," Journals of Gerontology A, vol. 57(6), pp. M347-M351, 2002.

dhe day-today work is work that requires effort or hard work and leisure time is done more than just watching TV. But for today's living conditions the definition may need to be reconsidered considering the number of daily activities that are too relaxed and time-fillers who only watch TV.

To that end, Pate proposes a definition of physical fitness that is expected to be more compatible with current conditions [11]. He defines physical fitness as the ability of the heart, blood, lungs, and muscles to function efficiently optimally. Whereas Ratliffe, itself defines physical fitness as a state of fit body condition that causes the person to be comfortable doing physically strenuous daily activities, reduces health risks related to lack of exercise / sport, and develops the basic foundations of fitness to participate in various physical activities [12]. Another definition adapted to the health fitness component contained in it was stated Rusli Lutan, namely the ability of a person to perform physical tasks that require strength, endurance, and flexibility [9].

\section{REFERENCES}

[1] W.J. Chodzko-Zajko, D.N. Proctor, M.A. Fiatarone Singh, "Exercise and physical activity for older adults," Medicine and Science in Sports and Exercise, vol. 41(7), pp. 1510-1530, 2009.

[3] Zhao G, Ford ES, Li C, Balluz LS, "Physical activity in U.S. Older adults with diabetes mellitus: prevalence and correlates of meeting physical activity recommendations," Journal of the American Geriatrics Society, vol. 59(1), pp. 132-137, 2011.

[4] United States Department of Health and Human Services, Physical Activity Guidelines for Americans. Washington, DC: U.S. Government Printing Office, 2008.

[5] J.F. Sallis \& K. Patrick, "Physical activity guidelines for adolescents: consensus statement," Pediatric exercise science, vol. 6(4), pp. 302-314, 1994.

[6] R.R. Pate, "Physical activity and health: dose-response issues," Research Quarterly for Exercise and Sport, vol. 66(4), pp. 313-317, 1995.

[7] Ministry of Health Republic of Indonesia, The Directorate General of Community Health: Technical Guidelines for Health Insurance Scheme for the Population in Health Centres and its networks. Jakarta Ministry of Health Republic of Indonesia - The Directorate General of Community Health, 2008.

[8] M.W. Morris \& K. Peng, "Culture and cause: American and Chinese attributions for social and physical events," Journal of Personality and Social psychology, vol. 67(6), pp. 949, 1994.

[9] Lutan Rusli. Towards Healthy and Fit. Jakarta: Depdiknas Ditjen Dikdasmen, 2002.

[10] AAHPERD, Physical Education for Lifelong Fitness: The Physical Best Teacher's Guide, Human Kinetics, 1999.

[11] R.R. Pate, "A new definition of youth fitness. The physician and sportsmedicine," vol. 11(4), pp. 77-83, 1983.

[12] T. Ratliffe \& L.M. Ratliffe, Teaching children fitness: Becoming a master teacher. Human Kinetics Publishers, 1994. 